\title{
Biochemical and Molecular Mechanisms of Platelet-Rich Plasma in Ameliorating Liver Fibrosis Induced by Dimethylnitrosurea
}

\author{
Neveen Salem ${ }^{a, b} \quad$ Amal Hamza ${ }^{a, c} \quad$ Hanan Alnahdi ${ }^{a} \quad N^{a j l a ~ A y a z ~}{ }^{a}$ \\ ${ }^{a}$ Applied Biochemistry Department, Faculty of Science, University of Jeddah, Jeddah, Saudi Arabia; \\ bNarcotics, Ergogenic Aids and Poisons Department, National Research Centre, Giza, Egypt; \\ 'Biochemistry and Nutrition Department, Faculty of Women, Ain Shams University, Cairo, Egypt
}

\section{Key Words}

PRP • Liver fibrosis - Liver enzymes - Inflammatory mediators - Fibrotic markers • Antiapoptotic markers

\begin{abstract}
Background/Aims: Hepatic fibrosis is a wound-healing process in the chronically injured liver. Clinical application of platelet-rich plasma (PRP) is of considerable interest for wound healing and regeneration. In view of the regeneration effect of PRP, we designed this study to explore the hypothesis that PRP could play a role in improving the biochemical and molecular changes that occur in liver fibrosis induced by dimethylnitrosamine (DMN) in rats. Methods: Four groups were studied: control, PRP control, DMN (liver fibrosis), and DMN+PRP groups. Serum liver enzymes (alanine amino transferase ALT, aspartate amino transferase AST, gamma glutamyl transferase GGT, and lactate dehydrogenase $L D H$ ), and liver hydroxyproline content were measured colorimetrically.Interleukin-8 (IL-8) and B-cell lymphoma (Bcl2) were determined by enzyme-linked immunosorbent assay. And the expression levels of alpha-smooth muscle actin $(\alpha-S M A)$, transforming growth factor (TGF- $\beta$ ), and nuclear factor kappa B1(NF-kB1) were evaluated by quantitative real-time polymerase chain reaction. Results: Our results showed that PRP markedly improved the DMN-induced changes in liver enzymes accompanied by a significant decrease in liver hydroxyproline content and IL-8 level induced by DMN, and an increase in the anti-apoptotic marker $\mathrm{Bcl}-2$. PRP also showed significant down-regulation of fibrosis-related genes $\alpha$-SMA and TGF- $\beta$ and a significant decrease in the inflammatory marker NF-қB1. Conclusion: Based on these encouraging results, we consider that PRP could be a promising new agent for liver regeneration and alleviation of fibrosis.
\end{abstract}

\section{Introduction}

The liver is the main organ involved in metabolism, detoxification, and secretory functions in the body, making it vulnerable to numerous disorders. Due to the lack of effective treatment for such disorders, research is ongoing to create new medications. The liver is 
a hematopoietic organ during the fetal period, and fully developed hepatocytes produce thrombopoietin, which can stimulate platelet production in the bone marrow [1].

Chronic liver disease (CLD) is a disease of the liver that involves progressive destruction and regeneration of the liver parenchyma, leading to fibrosis and cirrhosis, and is the main cause of liver-related mortality and morbidity worldwide. Liver fibrosis is a result of sustained wound-healing in response to chronic liver dysfunction induced by several factors [2].

Liver fibrosis has been commonly linked to CLDs and is a consequence of chronic inflammation. Mounting evidence has indicated that fibrosis is mainly attributed to an imbalance between the rates of synthesis and deposition of collagen which is observed in many metabolic and biochemical abnormalities. Moreover, multiple biological processes, including inflammation and hepatic stellate cell proliferation and activation, regulate the pathogenesis of hepatic fibrosis [3].

Chronic inflammation triggers the accumulation of collagen, which results from a series of events that drive proinflammatory cytokines, released by both liver-resident cells and circulating immune cells. These inflammatory stimuli enhance the activation of quiescent hepatic stellate cells (HSCs) to myofibroblast-like cells to produce collagen. When hepatic fibrosis occurs, collagen (especially types 1 and 3 ) proliferation accounts for $50 \%$ of the total protein in the fibrotic liver. With ongoing injury, fibrosis progresses to bridging fibrosis with nodule formation, ultimately leading to cirrhosis and hepatocellular carcinoma. Therefore, initial prevention of liver fibrosis is a critical strategy for halting CLD [4]. Although liver fibrosis has been considered an irreversible process, it has recently been suggested that even advanced fibrosis may be reversible. According to these recent studies, novel therapies have been developed to treat patients with cirrhosis [5].

Marx et al [6] was the first to investigate platelet-rich plasma (PRP), an autologous product rich in growth factors, acquired from a blood sample via centrifugation to separate the platelet-rich supernatant [7].The use of PRP in tissue regeneration is for a developing area of research for clinicians and specialists. Interestingly, PRP has a thrombotic impact. Platelets contain proteins required for hemostasis as well as numerous growth factors [1].

Furthermore, platelets have a prominent role in suppressing the progression of liver fibrosis in vitro and in vivo, and the elevation in growth factors induced by platelet transfusion can enhance liver function in patients with CLD and cirrhosis [8].Significant advantages of PRP compared with other methods of administering growth factors are that it is a cost-effective product and is simple to acquire, and there is no risk of rejection or immune response to autologous PRP. Additionally, antimicrobial activity of PRP containing leukocytes has been reported, suggesting a generally low risk of infection [9].

PRP has been the subject of interest for various clinical investigations; however, few studies have examined the impact of PRP infusion on liver fibrosis. Therefore, the goal of this study was to explore the hypothesis that PRP could play a role in counteracting the biochemical changes that occur during liver fibrosis induced experimentally in rats, to elucidate the biochemical and molecular mechanisms through which PRP induces its effects, and to consider future clinical application of PRP.

\section{Materials and Methods}

\section{Animals}

Forty adult male Wistar rats weighing 180-220 g were obtained from the Animal House Colony of the National Research Center (Cairo, Egypt). Rats were maintained under controlled conditions (temperature $25 \pm 1^{\circ} \mathrm{C}$, humidity $60 \pm 10 \%$, and a $12 / 12 \mathrm{~h}$ light/dark cycle). Rats were given 1 week for acclimatization before any test procedures and had free access to standard rodent chow and water. Experiments were conducted in accordance with the rules of the Ethical Committee of National Research Center, Egypt, which are consistent with the recommendations of the National Institutes of Health Guide for Care and Use of Laboratory Animals (Publication No. 85-23, revised1996). 


\section{Cellular Physiology Cell Physiol Biochem 2018;47:2331-2339 \\ \begin{tabular}{l|l} 
and Biochemistry Published online: July 06, 2018 & $\begin{array}{l}\text { (c) } 2018 \text { The Author(s). Published by S. Karger AG, Basel } \\
\text { www.karger.com/cpb }\end{array}$ \\
\hline
\end{tabular}}

Salem et al.: Platelet-rich Plasma on Liver Fibrosis

Chemicals

Dimethylnitrosamine (DMN) was obtained from Sigma Chemical Co. (St. Louis, MO, USA). All other chemicals and reagents used were of analytical grade

Preparation of platelet-rich plasma

PRP was prepared using the double centrifugation tube method [10]. Ten male Wistar rats were used as blood donors and anesthetized with ether, and $2 \mathrm{~mL}$ blood was collected using aseptic techniques from the retro-orbital plexus into tubes containing $0.3 \mathrm{~mL}$ (3.2\% sodium citrate) anticoagulant. Blood was centrifuged twice. The first centrifugation at $1600 \mathrm{rpm}$ for $10 \mathrm{~min}$ resulted in three different density compartments: the inferior layer containing red blood cells, the intermediate layer containing the buffy coat of white blood cells, and the superior layer containing plasma. The plasma was removed with a pipette and the portion just above the buffy coat was obtained without disturbing the buffy coat.

The plasma was centrifuged again at $2000 \mathrm{rpm}$ for $10 \mathrm{~min}$ to yield two portions: the top consisting of platelet-poor plasma (PPP) and the bottom consisting of the platelet button. PPP was discarded and the platelet button was gently agitated and then resuspended in phosphate-buffered saline (PBS) (1:1). Platelets were counted using a hematology analyzer (MICROS abc LC-152; Horiba Ltd., Kyoto, Japan; 1, 000, 000 cells $/ \mu \mathrm{L}$ ) and then frozen at $-80^{\circ} \mathrm{C}$ until use [11].PRP was activated immediately before use with $\mathrm{CaCl}_{2}$ $\left(0.8 \mathrm{~mL} \mathrm{PRP}+0.2 \mathrm{~mL} 10 \% \mathrm{CaCl}_{2}\right)$.

\section{Induction of hepatotoxicity}

Hepatotoxicity was induced by intraperitoneal injection of DMN (10 mg/kg body weight/day) on 3 consecutive days of each week for 3 weeks. DMN was diluted (1:100) with $0.15 \mathrm{M}$ sterile $\mathrm{NaCl}$ [4]

\section{PRP administration}

Activated PRP $(0.5 \mathrm{~mL})$ was placed in a sterile insulin syringe, and rats were injected subcutaneously twice weekly for 3 weeks [7].

\section{Study design}

Rats were assigned into four groups 10 rats per group as follow: (Control gp) Rats were injected with $0.5 \mathrm{ml}$ saline. (PRP control gp) Rats were injected with $0.5 \mathrm{ml}$ PRP. (DMN gp) Rats were received DMN and injected with $0.5 \mathrm{ml}$ saline. (DMN+PRP gp) Rats received DMN and injected with $0.5 \mathrm{ml}$ PRP.

At the end of the three weeks, blood samples from animals under study were collected via retro orbital bleeding after being anaesthetized by sodium thiopental injection $(50 \mathrm{mg} / \mathrm{kg})$ Then, the respective sera were separated and stored for subsequent enzymes measurements. The rats were then decapitated and their livers were carefully removed, washed with isotonic saline, and apart of liver tissue was kept in $10 \%$ formol/saline for histopathological investigation, and a second part were kept at -80 for gene expression and hydroxyproline estimation and the last part was homogenized with $0.1 \mathrm{M}$ phosphate buffer saline at pH7.4, to give a final concentration of $10 \% \mathrm{w} / \mathrm{v}$ and centrifuged at $3000 \mathrm{xg}$ for $15 \mathrm{~min}$ at $-4 \mathrm{C}$. The supernatant obtained was used for further biochemical assays

\section{Biochemical analysis}

Serum aspartate amino transferase (AST), alanine amino transferase (ALT), and gamma glutamyl transferase (GGT) activities were evaluated using kits provided by Stanbio Laboratory (Boerne, TX, USA) following the method of Reitman and Frankel [12].Serum lactate dehydrogenase (LDH) was assayed colorimetrically using kits from BioAssay Systems (Hayward, CA, USA according to the method of Henry [13].Hydroxyproline liver content was determined according to the method of Bergman and Loxley [14].Interleukin-8 (IL-8) andB-cell lymphoma 2 (Bcl-2) levels were estimated using enzyme-linked immunosorbent assay kits (Glory Science Co., Del Rio,TX, USA) according to the manufacturer's instructions.

\section{Quantitative Real Time-PCR ( $q R T-P C R$ )}

Gene expression levels were evaluated by quantitative real-time PCR using SYBR Green (Sigma Aldrich, CA,USA) and a Step One Real Time PCR system (Applied Biosystems, Foster City, CA, USA). The targets alphasmooth muscle actin ( $\alpha$-SMA), transforming growth factor (TGF)- $\beta$, and nuclear factor kappa B1 (NF- $\kappa B 1)$ were quantified relative to $\beta$-actin using the $2-\Delta \Delta$ CT method (Table 1 ). 
Histopathological investigation

Liver specimens were maintained in $10 \%$ formalin/saline and prepared in paraffin using standard techniques. The specimens were stained with hematoxylin and eosin and examined under a light microscope [15].

\section{Results}

Results of the analysis of enzyme activities are presented in Fig. 1. Treating rats with DMN induced a significant increase in serum ALT, AST, GGT, and LDH when compared with the healthy groups $(\mathrm{P} \leq 0.05)$. The PRP control group showed no significant change in liver enzyme activities compared with the Control group. Furthermore, the DMN+PRP group showed significant reduction in the activity of liver enzymes compared with the DMN group $(\mathrm{P} \leq 0.05)$.

Fig. 2 shows liver hydroxyl proline, IL-8, and Bcl-2 levels in all investigated groups. It is clear that liver hydroxyl proline and IL-8 levels were
Table 1. The sequences of primers of the genes used

\begin{tabular}{lr}
\hline Target genes & Forward (F) and reverse (R) Primers $\left(5^{\prime} \rightarrow 3^{\prime}\right)$ \\
\hline$\alpha$-SMA & F: GGCTCTGGGCTCTGTAAGG \\
& R: CTCTTGCTCTGGGCTTCATC \\
TGF- $\beta$ & F: ACCAACTACTGCTTCAGCTCCACA \\
& R: TGTACTGTGTGTCCAGGCTCCAAA
\end{tabular}

$\mathrm{NF}-\kappa \mathrm{B} 1$

F:CAAGCAGGAAGATGTGGTGGA

R: ATCATGTCCTTCTTTGGCAGCTA

F: GTG GGC CGC TCT AGG CAC CAA

$\beta$-Actin

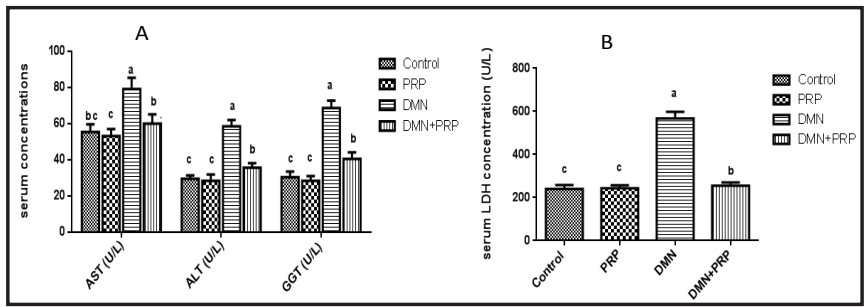

Fig. 1. Effect of PRP administration on serum AST,ALT, GGT, and LDH activities in DMN-treated rats. (A) AST:aspartate amino transferase,ALT:alanine amino transferase,GGT: Gamma Glutamyl transferase.(B)LDH: lactate dehydrogenase. Data are expressed as the mean \pm SEM $(n=10)$. Different letters indicate a significant difference between groups $(\mathrm{P}<0.05)$.

Fig. 2. Effect of PRP administration on liver hydroxyproline, IL8 , and $\mathrm{Bcl}-2$ levels in DMN-treated rats. (A) Hydroxproline. (B)IL-8: interleukin -8. (C) Bcl-2: B-cell lymphoma 2. Data are expressed as mean the \pm SEM $\quad(n=10)$. Different letters indicate a significant difference between groups $(\mathrm{P}<0.05)$.

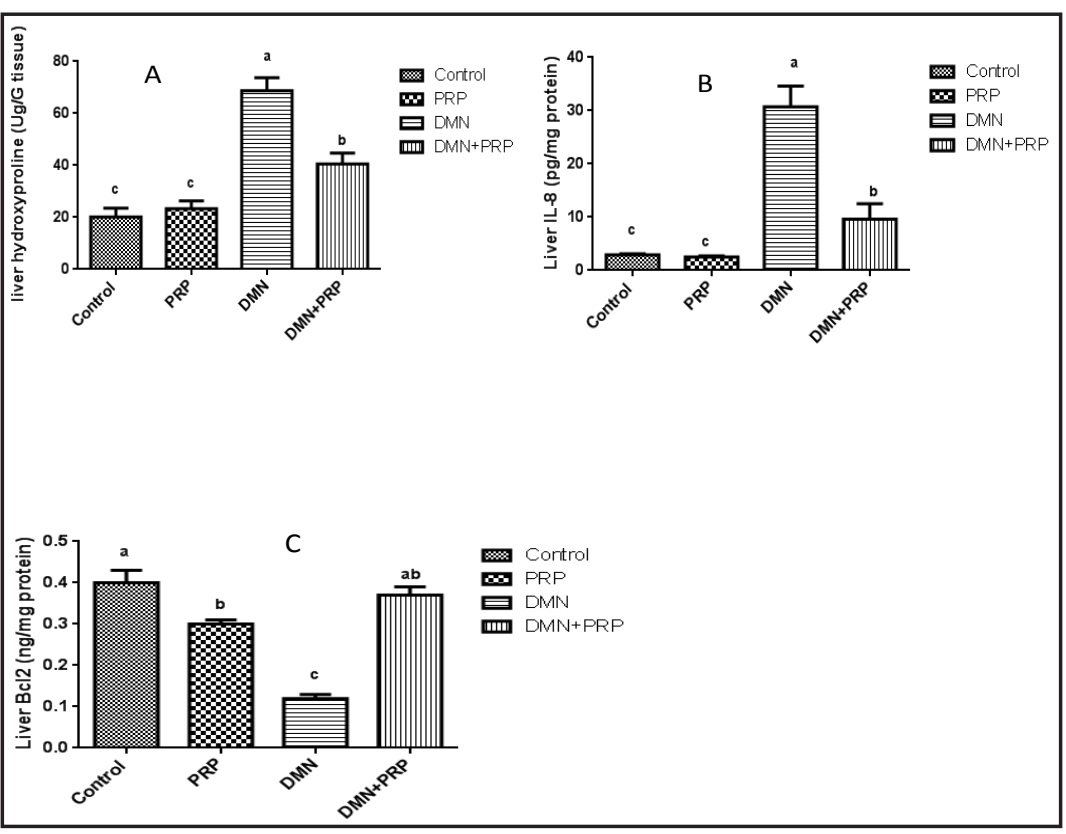




\section{Cellular Physiology Cell Physiol Biochem 2018:47:2331-2339 \begin{tabular}{c|c|c} 
DOI: 10.1159/000491544 & O 2018 The Author(s). Published by S. Karger AG, Basel \\
www.karger.com/cpb
\end{tabular}

Fig. 3. Effect of PRP administration on expression of the liver genes $\alpha$-SMA, TGF $\beta-1$ and NF-k $\beta 1$ in DMNtreated rats. (A) $\alpha$-SMA: alpha smooth muscle actin.(B) TGF $\beta$-1: transforming growth factor beta 1 (C) NF-k $\beta 1$ : nuclear factor kappa-light-chain-enhancer of activated B cells). Data are expressed as the mean \pm SEM $(n=10)$. Different letters indicate a significant difference between groups $(\mathrm{p}<0.05)$.
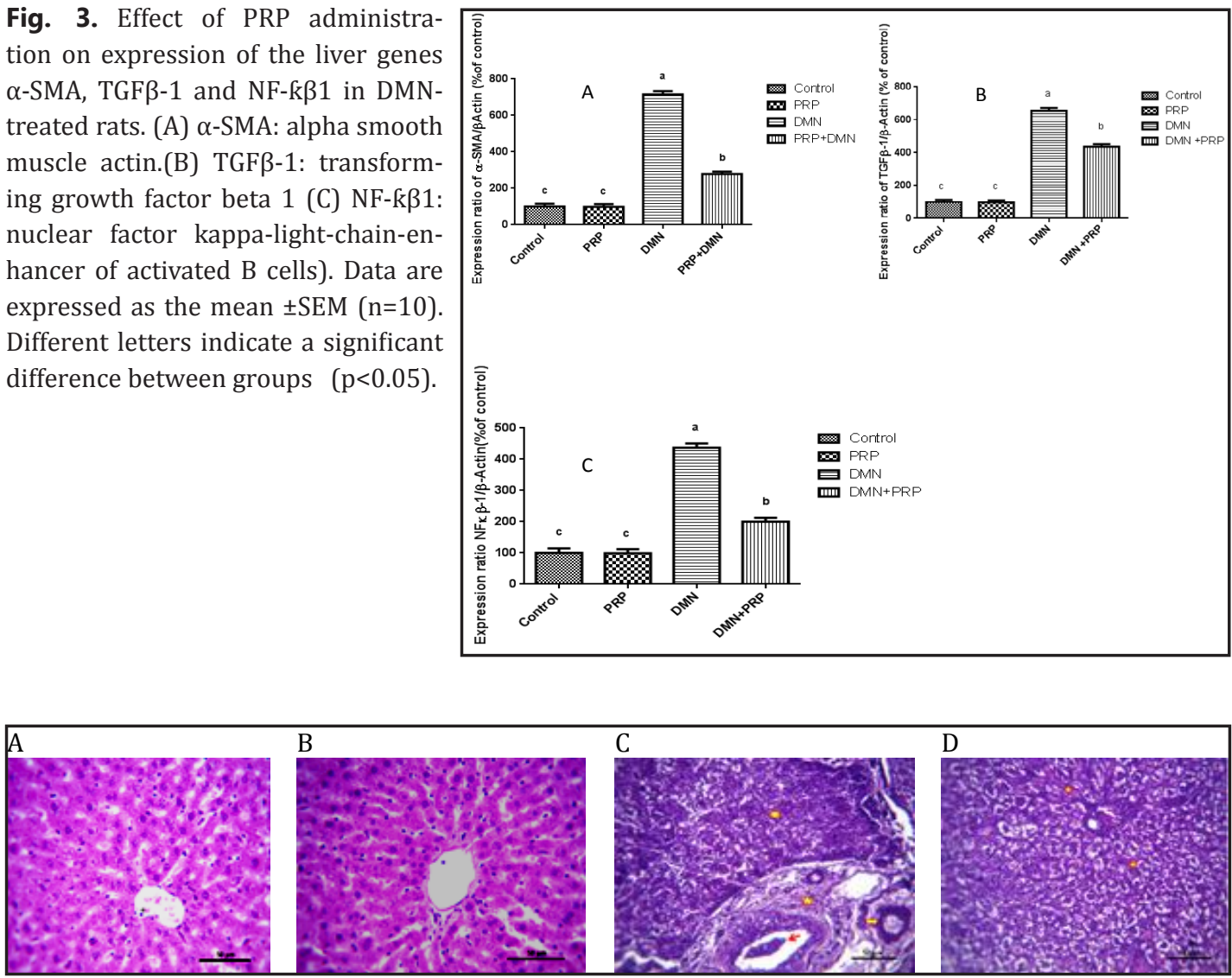

Fig. 4. Effect of PRP administration on hepatic histopathology in DMN-treated rats Photomicrographs of sections from hepatic tissue. (A) Control rats (saline) showed normal histomorphological architecture. (B) PRP rats (0.5 mL PRP)showed no histological modification. (C) DMN rats (10mg/kg DMN) showed periductular fibrosis (star), cholestasis in the bile duct (thin arrow), hyalinized blood vessels with endotheliosis (thick arrow), and necrosis and apoptosis inthe portal hepatic zone (arrow head). (D) DMN+PRP (10 mg/kg DMN + 0.5 mL PRP) rats showed widening and mild congested hepatic sinusoids (stars). Hematoxylin and eosin staining, Scale Bar $=50 \mu \mathrm{m}$.

significantly elevated while Bcl-2 was significantly reduced in the group treated with DMN compared with the healthy groups. In addition, our results revealed significant suppression of hydroxyl proline and IL-8 levels accompanied by a significantincrease inBcl-2 with PRP treatment $(\mathrm{P} \leq 0.05)$.

Gene expression levels of $\alpha$-SMA, TGF- $\beta$, and NF-kB in the investigated groups are shown in Fig. 3. As illustrated, gene expression was up-regulated in the DMN group compared with the Control group. Meanwhile, the DMN+PRP group showed significant down-regulation of these genes $(\mathrm{P} \leq 0.05)$.

Histopathological results are shown in Fig. 4. Photomicrographs of sections from hepatic tissue showed normal histomorphological architecture in the healthy and PRP-treated groups (Fig. 4A,B). Rats in the DMN group showed periductular fibrosis, cholestasis in the bile duct, hyalinized blood vessels with endotheliosis, necrosis and apoptosis , and portal hepatic zone (Fig. 4C). The DMN+PRP group showed widening and mild congested hepatic sinusoids (Fig. 4D). 


\section{Cellular Physiology Cell Physiol Biochem 2018;47:2331-2339 \\ \begin{tabular}{l|l} 
DOI: 10.1159/000491544 & Ond Biochemistry \\
Published online: July 06, 2018 & $\begin{array}{l}\text { 2018 The Author(s). Published by S. Karger AG, Basel } \\
\text { www.karger.com/cpb }\end{array}$
\end{tabular} \\ Salem et al.: Platelet-rich Plasma on Liver Fibrosis}

\section{Discussion}

Liver dysfunction mediates many pathological manifestations, including HSC proliferation, pro-inflammatory cytokine secretion, and extracellular matrix (ECM) protein deposition, with consequent propagation of liver fibrosis. In this study we used DMN to evoke hepatic dysfunction and fibrosis, then the therapeutic effect of PRP on DMN-induced hepatic fibrosis in rats was assessed. The results demonstrated that PRP provided significant protection against DMN-induced liver fibrosis mainly via antifibrotic, anti-apoptotic, and anti-inflammatory pathways.

DMN-induced hepatic insult is a key experimental model of hepatic fibrosis commonly utilized for preclinical assessment of agents with potential antifibrotic activity [16]. Hepatic fibrosis is considered a common response to chronic liver insults of different origin. In this study, we successfully induced liver fibrosis in experimental animals using DMN as evidenced by the elevation of liver enzymes (ALT, AST, GGT, and LDH), as well as the significant increase in liver hydroxyproline and IL-8 and significant reduction in Bcl-2 level. Our findings of up-regulated gene expression of the fibrotic markers TGF- $\beta$ and $\alpha$-SMA and inflammatory mediator NF-қB suggest that liver fibrosis was induced. This is consistent with the findings of Lee et al [17].. In addition, Ma et al [18]. reported that a single intraperitoneal injection of DMN $(30 \mathrm{mg} / \mathrm{kg}$ ) could effectively induce acute liver injury. It was proposed that DMN induces liver fibrosis directly through the destruction of HSCs and indirectly by enhancing production of reactive oxygen species.

DMN is predominantly utilized for the induction of liver cirrhosis and hepatocellular carcinoma. A single high-dose intraperitoneal injection could cause intense hepatic damage shown as severe necrosis associated with hemorrhage that mimics human hepatitis [19]. The adverse effects induced by DMN are due to its downstream metabolites, rather than the parent compound. The metabolic half-life is $10 \mathrm{~min}$ in rodents and around $20 \mathrm{~min}$ in primates [20]. The primary target of DMN is the liver, because the liver contains essential enzymes required for its metabolic activation [21]

At present, liver fibrosis is thought to be responsible for the dynamic process of constant ECM remodeling during chronic liver damage; this process prompts the accumulation of a few extracellular proteins, proteoglycans, and carbohydrates. Among the cellular populations in the liver, HSCs have been regarded to play a crucial role in mediating liver fibrosis through triggering ECM generation and TGF- $\beta$ secretion.It is well known that the main profibrogenic inducer, TGF- $\beta 1$, contributes to HSC activation,which seems to play a pivotal role in liver fibrogenesis [5].

It has been proposed that DMN treatment causes severe necrosis associated with enhanced deposition in the liver of ECM proteins, especially collagen [22]. This may explain the observed elevation in liver hydroxyproline level by DMN. The DMN-treated rats demonstrated apoptotic changes analogous to those found in patients with hepatic fibrosis and alcoholic cirrhosis associated with an elevated Bcl-2 level [21].

Additionally, liver fibrosis stimulates accumulation of inflammatory cells and platelets, HSC enactment, and cytokine release. The HSCs undergo a phenotypic transdifferentiation to contract myofibroblasts expressing $\alpha$-SMA. During liver fibrogenesis, TGF- $\beta 1$ causes an increase in HSC transit into myofibroblasts through the TGF- $\beta 1 /$ Smad signaling pathway [23], which stimulates ECM synthesis, including synthesis of collagen type II, and suppresses its degeneration [24]. Accumulation of ECM forms scarring, leading to deterioration of hepatic function [25]. These findings are consistent with the present findings.

PRP is an easy system to convey high concentrations of autologous growth factors. PRP treatment represents a novel approach in regenerative medicine and has received considerable interest over the past two decades [26]. PRP has been utilized as a part of therapeutic and surgical approaches in numerous fields, including dentistry, orthopedics, neurosurgery, ophthalmology, and maxillofacial and cosmetic surgery [27].

Our data demonstrate that PRP infusion caused notable liver regeneration in an experimental model. This is validated by the significant decrease in liver enzymes (ALT, AST, 


\section{Cellular Physiology Cell Physiol Biochem 2018;47:2331-2339 \begin{tabular}{l|l} 
DOI: 10.1159/000491544 & $\begin{array}{l}\text { O 2018 The Author(s). Published by S. Karger AG, Basel } \\
\text { www.karger.com/cpb }\end{array}$
\end{tabular} \\ Salem et al.: Platelet-rich Plasma on Liver Fibrosis}

GGT, and LDH). Moreover, PRP demonstrated reduced mRNA expression of fibrosis-related genes including TGF- $\beta, \alpha$-SMA and liver hydroxyproline as well as inflammatory mediator gene NF-қB and hepatic IL-8. Furthermore, there was a significant elevation in the levels of the anti-apoptotic marker Bcl-2 following PRP infusion. These outcomes are encouraging for the use of PRP in liver regeneration.

Liver recovery is an extremely complicated process that involves intercellular interaction between growth factors and cytokines, for example, hepatocyte growth factor (HGF), EGF, tumor necrosis factor $\alpha$ (TNF- $\alpha$ ), and IL-6 [28]. Hepatocytes are the primary cells to enter the cell cycle and undergo proliferation. Hepatocytes produce mitogenic signals for other types of liver cells, and every mediator drives the downstream cascades, which transfer hepatocytes from the quiescent state to the cell cycle [29].TNF- $\alpha / \mathrm{NF}-\kappa \mathrm{B}, \mathrm{IL}-6 /$ signal transducer and activator of interpretation 3 (STAT3), phosphatidylinositol-3-kinase (PI3K)/Akt, HGF/HFG receptor (cMet), and extracellular signal-regulated kinase 1/2 (ERK1/2) are all important pathways involved in liver recovery [30]. The aforementioned mechanisms clarify the role of PRP in improving liver fibrosis because of its high content of growth factors.

The regenerative impact of platelets in the liver comprises three pathways: a direct impact on hepatocytes, a favorable impact on liver sinusoidal endothelial cells, and a collaborative impact on Kupffer cells. Therefore, it was proposed that the expansion of platelets induced by platelet transfusion would enhance liver function in patients with CLD in the clinical setting [31]. Intercellular interactions between numerous growth factors and cytokines, including HGF, TNF- $\alpha$, IL-6, TGF- $\alpha$, and EGF, have vital roles. All of these growth factors and cytokines cause activation of downstream cascades, related to the advance of quiescent hepatocytes into the cell cycle and progression beyond the restriction point in G1 phase of the cycle [32].

Previous investigations showed that immediate contact between platelets and hepatocytes could evoke the release of soluble factors from platelets, for example IGF-1 and HGF, which are considered crucial mediators for liver recovery [33]. It was also found that exogenous platelets improve liver recovery. Meanwhile, growth factors, such as IGF-I, VEGF, and HGF, contribute to hepatocyte proliferation induced by platelets [34]. The growth factors promote hepatocyte mitosis, which eventually enhances liver recovery.

Our histopathological results confirmed the above biochemical and molecular analyses. We demonstrated the presence of periductular fibrosis, cholestasis in the bile duct, hyalinized blood vessels with endotheliosis, and necrosis and apoptosis in hepatic tissues after DMN administration. The DMN+PRP group revealed that hepatocytes restore apparently normal architecture (regeneration) with mild congested hepatic sinusoids.

Based on our results of anti-fibrotic, anti-apoptotic, and anti-inflammatory effects, platelet therapy could provide a new approach for the development of novel strategies for treatment of liver diseases. Moreover, PRP could be used as a complementary method to decrease the adverse effects of hepatotoxicants.

\section{Acknowledgements}

We would to thank Dr. Ahmed Alattar Professor of pathology for his cooperation.

\section{Disclosure Statement}

The authors declared no conflict of interests. No fund received. 


\section{Cellular Physiology Cell Physiol Biochem 2018;47:2331-2339 \begin{tabular}{c|c|c|} 
DOI: 10.1159/000491544 & Ond Biochemistry 2018 The Author(s). Published by S. Karger AG, Basel \\
wwww.karger.com/cpb
\end{tabular}}

Salem et al.: Platelet-rich Plasma on Liver Fibrosis

\section{References}

1 Hesami Z, Jamshidzadeh A, Ayatollahi M, Geramizadeh B, Farshad 0 : Effect of Platelet-Rich Plasma on CCl 4 -Induced Chronic Liver Injury inMale Rats. Int J Hepatol 2014;14:1-7.

2 Bataller R, Brenner DA: Liver fibrosis. J. Clin Invest 2005; 15:209-218.

-3 Xuan J, Wen W, Wang Y, Wang F, Xu HB, Shao M, Yang Y, Tian YZ: Effect of Huagantongluofang, a Chinese Traditional Medicine, in Hepatic Fibrogenesis in a Mouse Model of Biliary Cirrhosis. Cell Physiol Biochem 2017;44:368-376.

4 Abo El-Magd N, El-Karef A, El-Shishtawy M, Eissa L: Hepatoprotective effects of glycyrrhizin and omega-3 fatty acids on Nuclear Factor-kappa B pathway in thioacetamide-induced fibrosis in rats. EgyptianJ.Basic Appl Sci 2015;2;65-74.

5 Yu F, Chen B, Fan X, Li G, Dong P, Zheng J: Epigenetically-Regulated MicroRNA-9-5p Suppresses the Activation of Hepatic Stellate Cells via TGFBR1 and TGFBR2. Cell Physiol Biochem 2017;43:2242-2252.

6 Marx RE, Carlson ER, Eichstaedt RM : Platelet-rich plasma: Growth factor enhancement for bone grafts. Oral Surg Oral Med Oral Pathol Oral Radiol Endod 1998;85:638-46.

7 Lee JW, Kwon OH, Kim TK, Cho YK, Choi KY, Chung HY: Platelet-rich plasma: quantitative assessment of growth factor levels and comparative analysis of activated and inactivated groups. Arch Plast Surg 2013;40:530-535.

8 Maruyama T, Murata S, Takahashi K : Platelet transfusion improves liver function in patients with chronic liver disease and cirrhosis. Tohoku J Exp Med 2013;229:213-220.

-9 Bielecki TM, Gazdzik TS, Arendt J, Szczepanski T, Krol W, Wielkoszynski T: Antibacterial effect of autologous platelet gel enriched with growth factors and other active substances: an in vitro study. J Bone Joint Surg Br 2007;89:417-420.

10 Pazzini JM, Nardi AB, Huppes RR, Gering AP, Ferreira MG :Method to obtain platelet-rich plasma from rabbits (Oryctolaguscuniculus). Pesq. Vet. Bras 2016;36: 39-44.

11 Kazemnejad S, Allameh A, Gharehbaghian A, Soleimani M, Amirizadeh N, Jazayeri M: Efficient replacing of fetal bovine serum with human platelet releasate during propagation and differentiation of human bone marrow-derived mesenchymal stem cells to functional hepatocytes-like cells. VoxSanguinis 2008;95:149158.

12 Reitman S, Frankel S: The colorimetric method for determination of serum Saunders and Company, Philadelphia, PA, 1957;pp 365.

13 Henry JB: Clinical Diagnosis and Management by Laboratory Methods. WB 1979;559-634.

14 Bergman I, Loxley R: New spectrophotometric method for the determination of proline in tissue hydrolyzates Anal. Chem1970;42:702-706.

15 Bancroft JD, Stevens A, Turner DR: Theory and practice of histological techniques: Churchill Livingstone New York. the text 1996;766.

-16 Jung KH, Harg SW, Zheng HM, Lee DH, Hong SS: Melatonine downregulates nuclear erythroid-2-related factor 2 and nuclear factor kappa-B during prevention of oxidative liver injury in a dimethylnitrosamine model. J Pineal Res 2009;47:173-183.

17 Lee M, Yoon S, Moon J: The flavonoid Naringenin Inhibits Dimethylnitrosamine -Induced Liver Damage in Rats. Biol Pharm Bull 2004;27:72-76.

18 Ma S, Lv L, Lu Q, Li Y, Zhang F, Lin M, Gao D, Liu K, Tian X, Yao J: Gallic Acid Attenuates Dimethylnitrosamine-induced Acute Liver Injury in Mice through Nrf2-mediated Induction of Heme Oxygenase-1 and Glutathione-s-transferase Alpha 3. Med Chem 2014;4:9.

19 Oyaizu T, Shikata N, Senzaki H, Matsuzawa A, Tsubura A: Studies on the mechanism of dimethylnitrosamine induced acute liver injury in mice. Exp Toxicol Pathol 1997;49:375-380.

20 Anderson LM, Koseniauskas R, Burak ES, Moskal TJ, Gombar CT, Phillips JM, Sansone EB, Keimig S, Magee PN, Rice JM, Harrington GW: Reduced blood clearance and increased urinary excretion of $\mathrm{N}$-nitrosodimethylamine in patas monkeys exposed to ethanol or isopropyl alcohol. Cancer Res 1992;52:1463-1468.

21 George J, Ramesh Rao K, Stern R, Chandrakasan G: Dimethylnitrosamine -induced liver injury in rats: the early deposition of collagen. Toxicology 2001;156:129-138. 


\section{Cellular Physiology Cell Physiol Biochem 2018;47:2331-2339 \begin{tabular}{l|l} 
DOI: 10.1159/000491544 & $\begin{array}{l}\text { O 2018 The Author(s). Published by S. Karger AG, Basel } \\
\text { www.karger.com/cpb }\end{array}$
\end{tabular}}

Salem et al.: Platelet-rich Plasma on Liver Fibrosis

22 Savolainen ER, Brocks D, Ala-Kokko L, Kivirikko KI : Serum concentrations of the $N$-terryinalpropeptide of type III procollagen and two type IV collagen fragments and gene expression of the respective collagen types in liver in rats with dimethylnitrosamine-induced hepatic fibrosis. Biochem J 1988;249:753-757.

23 Yu F, Yang J, Huang K, Pan X, Chen B, Dong P, Zheng J: The Epigenetically-Regulated microRNA-378a Targets TGF- $\beta 2$ in TGF- $\beta 1$-Treated Hepatic Stellate Cells. Cell Physiol Biochem 2016;40:183-194.

24 Hong S W, Jung K H, Zheng HM, Lee HS, Suh JK, Park I, Lee DH, Hong SS: The Protective Effect of Resveratrol on Dimethylnitrosamine-Induced Liver Fibrosis in Rats.Arch Pharm Res 2010;33:601-609.

-25 Wang Z, Li Q, Xiang M, Zhang F, Wei D, Wen Z, Zhou Y: Astragaloside alleviates hepatic Fibrosis Function via PAR2 Signaling Pathway in Diabetic Rats. Cell Physiol Biochem 2017;41:1156-1166.

26 Pavlovic V, Ciric M, Jovanovic V, Stojanovic P :Platelet rich plasma: A short overview of certain bioactive components. Open Medicine 2016;11:242-247.

27 El-Tahawy N, Rifaai1 RA, Saber EA, Saied SR, Ibrah RA: Effect of Platelet Rich Plasma (PRP) Injection on the Endocrine Pancreas of the Experimentally Induced Diabetes in Male Albino Rats: A Histological and Immunohistochemical Study. J Diabetes Metab 2017;8:3

28 Gilgenkrantz H, Colin de Hortet A: New insights into liver regeneration Clin Res Hepatol Gastroentestinal 2011;35:623-629.

29 Ozaki M: Role of Jak/STAT 3 and PL3-K/AKT pathways in liver injury and regeneration. Seikagaku 2008;80:399-408.

-30 Chen XQ Xu CS, Liu YM : Involvement of ERK $1 \frac{1}{2}$ signaling in proliferation of eight liver cell types during hepatic regeneration in rats. Genet Mol Res 2013;12:665-677.

31 Takahashi K, Murata S ,Ohkohchi N: Platelets and Liver Regeneration. Austin J Surg 2014;:4.

32 Malik R, Selden C, Hodgson H: The role of non-parenchymal cells in liver growth.Semin. Cell Dev Biol 2002;13:425-431.

33 Ohkohchi N, Murata S, and Takahashi K: Platelet and Liver Regeneration In" Tissue Regeneration from Basic Biology to Clinical Application” InTech 2012;109-144.

34 Matsuo R, Ohkohchi N, Murata S:Platelets strongly induce hepatocyte proliferation with IGF-1 and HGF in vitro J Surg Res 2008;145:279-286. 